\title{
CHINAS E PRENDAS: IMAGENS DA MULHER GAÚCHA NO DISCURSO DE DOIS DICIONÁRIOS REGIONALISTAS
}

\author{
Valeria Schwuchow ${ }^{77}$ \\ Felipe Rodrigues Echevarria ${ }^{78}$
}

RESUMO: Nosso trabalho tem como perspectiva teórico-metodológico a História das Ideias Linguísticas (HIL) e seu corpus consiste em analisar dois verbetes típicos do linguajar gaúcho: china e prenda, ambos recortados de dois dicionários regionalistas: Vocabulario Gaúcho (1928), da autoria de Roque Callage e Dicionário de Regionalismos do Rio Grande do Sul (1984), da autoria de Zeno Cardoso Nunes e Rui Cardoso Nunes. Intentamos observar se os sentidos dos dois verbetes são mantidos e/ou atualizados nos dois dicionários produzidos em anos distintos, porém no mesmo século, nesse caso o século XX. Tomamos gramáticas e dicionários como instrumentos linguísticos sob a perspectiva da HIL. Esses instrumentos linguísticos, de acordo com Auroux (2014), até os dias de hoje são considerados os pilares de nosso saber metalinguístico. Abordar a HIL em nosso trabalho é imprescindivel, pois essa área do conhecimento estuda a produção de gramáticas e dicionários feita no Brasil desde o século XVI. Abordamos também a questão dos dicionários regionalistas, já que entendemos que os dicionários de regionalismos contribuem para a preservação do léxico gaúcho, e, segundo Petri (2009), também preservam uma identidade regional. A mesma autora afirma que dicionários mantêm e ao mesmo tempo atualizam sentidos. Foi o que percebemos ao analisar os sentidos de china e prenda em Vocabulario Gaúcho e Dicionário de Regionalismos do Rio Grande do Sul: os sentidos se mantêm praticamente os mesmos e há pouca atualização.

Palavras-chave: Dicionários; Dicionários Regionalistas; História das Ideias Linguísticas.

RESUMEN: Nuestro trabajo tiene como perspectiva teóricometodológica la Historia de las Ideas Lingüísticas (HIL) y su como

\footnotetext{
${ }^{77}$ Mestranda em Estudos Linguisticos na Universidade Federal de Santa Maria-UFSM

${ }^{78}$ Mestrando em Estudos Linguisticos na Universidade Federal de Santa Maria-UFSM
} 
objetivo analizar dos palabras típicas del lenguaje gaucho: china y prenda, ambas tomadas de dos diccionarios regionalistas: Vocabulario Gaúcho (1928), de Roque Callage y Dicionário de Regionalismos do Rio Grande do Sul (1984), de Zeno Cardoso Nunes y Rui Cardoso Nunes. Intentamos observar si los sentidos de estos vocablos son mantenidos y/o actualizados en los diccionarios producidos en años distintos, pero en el mismo siglo, en este caso, el siglo XX. Tomamos las gramáticas y los diccionarios como instrumentos lingüísticos bajo la perspectiva de la HIL. Estos instrumentos lingüísticos, de acuerdo con Auroux (2014), son considerados, hasta hoy, los pilares de nuestro saber metalingüístico. Abordar a través de la HIL nuestro trabajo es imprescindible, pues esta área del conocimiento estudia la producción de gramáticas y diccionarios hechos en Brasil desde el siglo XVI. Abordamos también la cuestión de los diccionarios regionalistas, pues entendemos que los diccionarios de regionalismos contribuyen a la preservación del léxico gaucho y, según Petri (2009), también preservan una identidad regional. La misma autora afirma que los diccionarios mantienen y al mismo tiempo actualizan sentidos. Y fue esto lo que encontramos al analizar los sentidos de china y prenda en el Vocabulario Gaúcho y el Dicionário de Regionalismos do Rio Grande do Sul: los sentidos se mantienen y hay poca actualización.

Palabras-claves: Diccionarios; Diccionarios Regionalistas; Historia de las Ideas Lingüisticas.

\section{Introdução}

O dicionário, assim como a gramática, é tomado como instrumento linguístico e, segundo Auroux (2014), dicionários e gramáticas são até hoje os pilares de nossos saberes metalinguísticos. Neste trabalho, é o dicionário que vem a ser objeto de análise e que nos fornece dois verbetes que constituem o corpus do nosso artigo. Os dicionários são Vocabulario Gaúcho (1928), da autoria de Roque Callage e Dicionário de Regionalismos do Rio Grande do Sul (1984), da autoria de Zeno Cardoso Nunes e Rui Cardoso Nunes. São considerados regionalistas porque trazem verbetes típicos usados pelos falantes do Rio Grande do Sul, ou seja, apresentam o modo de falar de uma determinada região. Segundo Nunes (2001), o dicionário de termos regionalistas é "um conjunto de modos de dizer de uma sociedade" (p. 101), o qual apresenta um repertório popular próprio de um sujeito que vive fora dos grandes centros urbanos, mostrando, também, a reprodução de práticas sociais 
Chinas e prendas:

imagens da mulher gaúcha no discurso de dois dicionários regionalistas | 201 encenadas em contextos históricos específicos. O linguajar típico de uma determinada região nem sempre é abarcado pelo dicionário nacional, pois muitas vezes o modo de falar das pessoas dessas regiões foge da norma culta, daí a importância e a função do dicionário regionalista.

Primeiramente, abordamos a importância da História das Ideias Linguísticas para o conhecimento sobre a produção de dicionários que se faz no Brasil. É esse campo do saber que vem a dar um olhar diferenciado para o dicionário e que ajuda a desconstruir ideias simplistas acerca dos dicionários, que já foram vistos apenas como objetos para pesquisa e esclarecimento de dúvidas. Por isso, trazemos alguns pressupostos teóricos de autores importantes dentro da História das Ideias Linguísticas, que nos levam a entender que o dicionário é também um objeto discursivo, pois através dele podemos perceber e analisar um discurso que se manifesta nos verbetes e que tem uma relação direta com a história em que está inserido. Elucidamos também que a produção de gramáticas e dicionários feita por autores brasileiros fez com que o Brasil se tornasse cada vez mais desvencilhado de Portugal.

Apresentamos, também, aspectos sociais e históricos do Rio Grande do Sul, pois é ele que é o cenário que contextualiza os dois dicionários regionalistas que analisamos. Entendemos que a figura do gaúcho se constitui pela história do Estado e passa a ser reconhecido como um homem viril e hábil com atividades relacionadas ao campo. Questões geográficas como as fronteiras com Argentina e Uruguai influenciam o linguajar do gaúcho. Como nos diz Roque Callage (1928), de todas as influências que o linguajar gaúcho sofre, a maior é a influência platina. Essas questões sociais e aspectos históricos do Rio Grande do Sul são também as condições de produção dos dois dicionários analisados.

Petri (2009) afirma que dicionários atualizam e ao mesmo tempo mantém sentidos. Usamos esse pressuposto teórico para analisar quais os sentidos que os verbetes prenda e china apresentam em Vocabulario Regionalista e Dicionário de Regionalismos do Rio Grande do Sul. Observamos de que modo eles são mantidos e/ou atualizados em dicionários de anos distintos (o primeiro produzido em 1928 e o outro em 1984). Os sentidos trazidos pelos dois verbetes nos permitem ter uma ideia das condições sócio-históricos em que estão inseridos. 
202 | Valeria Schwuchow e Felipe Rodrigues Echevarria

1. A História das Ideias Linguísticas e seu olhar diferenciado para o dicionário

Falar sobre instrumentos linguísticos requer elucidar sobre a História das Ideias Linguísticas (HIL), visto que essa área do saber pesquisa e produz saberes sobre dicionários. Em seus estudos sobre o dicionário, a HIL dá a esse instrumento linguístico um olhar diferenciado, pois entende que ele não é apenas um lugar de consulta; é também um objeto discursivo. Segundo Nunes (2008), a HIL teve início no Brasil através de uma cooperação entre a Universidade Estadual de Campinas e a Universidade Paris 7, na França. A colaboração entre a equipe brasileira, guiada por Eni Orlandi e a equipe francesa, coordenada por Sylvain Auroux, consolidou a HIL no Brasil, cujos objetivos eram compreender a história do saber metalinguístico e constituição da língua nacional. Entendemos que a HIL, tanto no Brasil quanto na França, tem como foco o estudo da língua, seja no saber sobre a língua ou no discurso que se faz sobre ela.

Gramáticas e dicionários são tomados como instrumentos linguísticos sob a perspectiva da HIL. Esses instrumentos linguísticos, de acordo com Auroux (2014), "são ainda hoje os pilares de nosso saber metalinguístico” (p. 65). É através do dicionário e da gramática que acontece o processo de gramatização, pois eles permitem "descrever e instrumentar uma língua” (AUROUX, 2014, p. 65). Segundo o autor, depois da escrita, a gramatização vem a ser a segunda revolução tecnológica nos estudos da linguagem.

Para Nunes (2008), antes da HIL, os dicionários eram vistos apenas como objetos normativos. "Na linguística moderna, saussuriana, tais estudos foram considerados como objetos normativos, ou seja, não descritivos, portanto não científicos" (NUNES, 2008, p. 110).

Os dicionários, - no sentido em que entendemos hoje não faziam parte da tradição linguística inicial. Para nós, com efeito, uma gramática dá procedimentos gerais para engendrar/decompor enunciados, enquanto o dicionário fornece os itens que se trata de arranjar/interpretar segundo esse procedimento (AUROUX, 2014, p. 72).

Nesse sentido, a HIL vem a dar outro enfoque para os dicionários e outros instrumentos linguísticos; pois ela os transforma "em objetos vivos, partes de um processo em que os sujeitos se constituem em suas relações e tomam parte na construção histórica das formações sociais com 
Chinas e prendas:

imagens da mulher gaúcha no discurso de dois dicionários regionalistas | 203 suas instituições, e sua ordem cotidiana” (ORLANDI, 2001, p. 8). O dicionário, para Nunes (2001), é um lugar de observação do léxico; é um "objeto discursivo" (p. 101), sendo assim sua função não é meramente normativa. De acordo com Orlandi (2002), o instrumento linguístico, seja ele a gramática ou o dicionário, representa a relação dos falantes com a sua língua, atribuindo a essa uma realidade histórica.

\section{O processo de colonização linguística no Brasil}

A produção de dicionários no Brasil, como afirma Nunes (2008), está diretamente ligada com sua colonização. Antes de elucidarmos alguns pontos importantes da produção nacional de dicionários, pensamos que é pertinente mobilizar alguns conceitos, como os de colonização e descolonização linguística. Em sua obra intitulada Colonização linguística, Mariani (2004) entende a noção de colonização como a "coexistência de povos com histórias e línguas distintas em um dado momento histórico" (p. 23). Porém, conforme a autora, essa convivência nem sempre é pacífica, pois a língua do povo colonizador acaba se impondo à língua do povo colonizado.

[...] para a metrópole portuguesa, o exercício de uma política unitária de imposição da língua portuguesa representava a possibilidade de domesticação e absorção das diferenças de povos e culturas indígenas que se encontravam fora dos parâmetros do que se entendia como civilização na época. [...]

$\mathrm{O}$ caso da língua portuguesa frente às línguas indígenas é o da imposição da língua do conquistador. Língua essa que, por ser de domínio comum da nação portuguesa, supõe, ainda que imaginariamente, um entendimento entre o rei e seus súditos (MARIANI, 2008, p. 26).

○ processo de colonização linguística teve início no Brasil, segundo Orlandi (2009), com os missionários e foi se fortalecendo através dos relatos dos primeiros viajantes e com os naturalistas no período colonial. A colonização realizada pelos missionários foi realizada por meio do latim. Ao tomarem o latim como modelo, esses viajantes deparavam-se com outras línguas já existentes no Brasil e a incompreensão das mesmas fez com que houvesse o silenciamento delas. $O$ processo de colonização linguística supõe também a "imposição de idéias linguísticas vigentes na 
204 | Valeria Schwuchow e Felipe Rodrigues Echevarria

metrópole e um imaginário colonizador enlaçando língua e nação em um projeto único" (MARIANI, 2004, p. 25). Entendemos que esta "imposição de idéias linguísticas" se materializou em forma de gramáticas e dicionários da língua portuguesa que atendessem às necessidades dos falantes dessa língua em diferentes territórios, inclusive no território do Brasil.

Pela análise de materiais como os Relatos de missionários e viajantes que frequentaram o Brasil desde os inícios de sua formação, e, mais tarde, os naturalistas, podemos entrever o modo como representam e instrumentalizam a lingua no período colonial. Vemos, nesses materiais, como se inicia aí uma forma de conhecimento colonizador que significa de acordo com o projeto civilizatório europeu estabelecendo ao mesmo tempo um discurso sobre o Brasil e os brasileiros.

Como fica a questão da língua nestas condições? Como se sabe, para termos uma lingua nacional, no momento histórico em que o Brasil está subjugado por Portugal, o processo colonizador instala seu poder de dominação desqualificando o número enorme das outras línguas que aqui se falavam. Dá-se assim o confronto entre o Português e as várias línguas aqui existentes, representadas historicamente pelo Tupi (ORLANDI, 2009, p. 173).

Já a descolonização linguística, entendemos como um processo justamente ao contrário da colonização linguística. A descolonização linguística caracteriza-se pelo momento em que o Brasil passa a produzir sua própria gramatização. Essa produção se intensifica no século XIX, quando autores brasileiros começam a fazer dicionários e gramáticas. "Toda essa produção de dicionários parciais e de complemento mostra que no século XIX já se constituíra uma lexicografia brasileira da língua nacional" (NUNES, 2008, p. 10). Orlandi (2009) afirma que a as gramáticas próprias são "escritas por brasileiros para brasileiros" (p. 175). Segundo Sousa (2012), com a consolidação da língua portuguesa no Brasil, o processo de gramatização "se torna parte de um movimento de constituição política e social da identidade do falante do português brasileiro. Assim, o processo é visto como fazendo parte de um novo espaço de produção linguística" (p. 156). 
Chinas e prendas:

imagens da mulher gaúcha no discurso de dois dicionários regionalistas | 205 [...] o processo de gramatização do português do Brasil, passado o período das anotações de diários e relatos de viagens, da incorporação de brasileirismos nas gramáticas portuguesas, concretiza-se com a autoria brasileira na produção de instrumentos linguísticos, quando se publicam Gramáticas, Dicionários e Vocabulários de autores brasileiros, no século XIX, logo após a Independência do Brasil (STURZA, 2006, p. 01).

No século XX, surgiram os primeiros grandes dicionários monolíngues brasileiros de língua portuguesa. "Nesse período, os dicionários brasileiros passam a ser mais utilizados que os dicionários portugueses" (NUNES, 2008, p. 11). E é nesse cenário de produção nacional de dicionários que surgem os dicionários regionalistas.

3. O dicionário regionalista: lugar de preservação do léxico e da identidade gaúcha

Antes de entrarmos na questão dos dicionários regionalistas, convém trazer noções acerca do que é regionalismo. A questão regional no que diz respeito ao sul rio-grandense perpassa pelo debate sobre a identidade do gaúcho, sujeito central da cultural regional, em torno do qual emerge toda uma cultura a ser descrita por verbetes específicos, distintos daqueles (re)conhecidos no Português Brasileiro.

O que ocorre no Rio Grande do Sul parece estar indicando que atualmente só se chega ao nacional através do regional, ou seja, para seus habitantes só é possível ser brasileiro sendo gaúcho antes. A identidade gaúcha é hoje resposta enquanto expressão de uma distinção cultural em um país que se encontra integrado do ponto de vista econômico, cultural e de redes de transporte de comunicação (OLIVEN, 2006, p. 14).

Sob essa perspectiva, entendemos que o regionalismo é um "campo de disputas no quais grupos com diferentes posições e interesses se enfrentam” (OLIVEN, 2006, p. 25). Compreender que existem diferentes identidades regionais no Brasil faz com que se valorizem as diferenças culturais, como uma forma de não ceder a uma homogeneização cultural. Nesse contexto, interessa-nos saber mais acerca 
206 | Valeria Schwuchow e Felipe Rodrigues Echevarria

dos dicionários regionalistas, que servem justamente para marcar essas diferenças e preservá-las.

Dicionários de regionalismos e brasileirismos também são conhecidos como dicionários sobre o povo. Segundo Nunes (2006), eles apareceram no final do século XIX e serviam como complemento aos dicionários portugueses. $\mathrm{O}$ Brasil, nesse período, vivia um momento de afirmação de uma língua nacional e o discurso sobre o povo era formulado no dicionário. Sujeitos típicos do país, como índios, mulatos, quilombolas e baianos tinham suas definições apresentadas nesses dicionários sobre o povo. Essas obras tinham como principal objeto o povo brasileiro, mas elas não eram destinadas a um público amplo, sendo assim despertavam interesse mais especificamente nos estudiosos da lingua nacional.

O Brasil do século XIX é um país predominantemente rural, mas o dicionário é feito para os letrados, nos centros urbanos em desenvolvimento, como Rio de Janeiro e Porto Alegre. $O$ dicionário sobre o povo faz aparecer as palavras do povo brasileiro e lhes atribui um estatuto lingüístico nacional ou regional. Isto funciona como um argumento para estabelecer a diferença entre o português brasileiro e o português de Portugal (NUNES, 2006, p. 2).

Em dicionários regionalistas do Rio Grande do Sul, existem sentidos promovidos pelos falantes daquela região. Como afirma Petri (2010), trata-se da manutenção de saberes, da manutenção de uma história, de uma identidade dita como "gaúcha", via especificidade linguística. Essa identidade se perpetua com a ajuda do dicionário. Auroux (2014) considera o dicionário um instrumento linguístico que serve não só de base para a construção de conhecimentos, mas também para representar uma materialidade discursiva de perpetuação linguística. Consideramos que os dicionários de regionalismos funcionam como preservação do léxico gaúcho, da mesma maneira que preservam uma identidade regional.

4. As condições de produção de Vocabulario Gaúcho e Dicionário de Regionalismos do Rio Grande do Sul

Os instrumentos linguísticos que servem como objeto de análise do nosso trabalho são justamente dois dicionários regionalistas. Um é 
Chinas e prendas:

imagens da mulher gaúcha no discurso de dois dicionários regionalistas | 207 Vocabulario Gaúcho, do autor Roque Callage, produzido em 1928. O outro é o Dicionário de Regionalismos do Rio Grande do Sul, de Zeno Cardoso Nunes e Rui Cardoso Nunes, publicado em 1984. Consideramos que todo dicionário é produzido sob certas condições de produção:

[...] o dicionário não é algo que estaria na mente das pessoas desde que elas nascem, mas, sim, algo que é produzido por práticas reais em determinadas conjunturas sociais, ou seja, o dicionário é produzido sob certas "condições de produção dos discursos". E as palavras não são tomadas como algo abstrato, sem relação com os sujeitos e as circunstâncias em que eles se encontram, mas sim como resultantes das relações sociais e históricas, relações essas que são complexas e, por vezes, polêmicas ou contraditórias. Assim, o dicionário é visto como um discurso sobre a língua, mais especificamente sobre as palavras ou sobre um setor da realidade, para um público leitor, em certas condições sociais e históricas (NUNES, 2010, p. 7).

As condições de produção compreendem os sujeitos e a situação. Segundo Orlandi (2005),

Podemos considerar as condições de produção em sentido escrito e temos as circunstâncias da enunciação: é o contexto imediato. E se a consideramos em sentido amplo, as condições de produção incluem o contexto sóciohistórico, ideológico (p. 30).

Ainda para a autora, as condições de produção constituem os discursos e dependem de certos fatores para funcionar. Um desses fatores é a relação de sentidos, que explica que "não há discurso que não se relacione com outros" (ORLANDI, 2005, p. 39). Esses sentidos resultam de relações, de maneira que todo discurso é sustentado por outro assim como pode apontar dizeres futuros. Sendo assim, compreendemos que o discurso não pode abarcar um começo absoluto tampouco um ponto final. Com o conceito de condições de produção, a história é colocada em um patamar importante, devendo ser vista como a análise das transformações das quais as sociedades são efetivamente capazes. "As duas 
noções fundamentais da história (...) não são mais o tempo e o passado, mas a mudança e o acontecimento" (FOUCAULT, [1970] 2001 p. 287).

E quais seriam as condições de produção dos dois dicionários que são o objeto de análise do presente artigo? Ambos foram produzidos no século XX e no Rio Grande do Sul e tal fato nos faz apresentar algumas questões. Geograficamente, o estado do Rio Grande do Sul é "o mais meridional estado brasileiro, com um território de $282.184^{2}$ que se estende do oceano atlântico até as planícies que constituem parte da fronteira brasileira com a Argentina e com o Uruguai" (EIZIRIK, 2002, p. 137).

Quanto à formação étnica e social do Rio Grande do Sul, existem duas vertentes que explicam essa formação: a matriz lusa e a matriz platina. Conforme Neumann (1994), a matriz lusa destaca a grande influência e importância da colonização portuguesa, pois foi determinante na formação do gaúcho do Rio Grande do Sul como tipo social. A outra matriz é a platina, que de acordo com o mesmo autor, determina a formação do gaúcho no espaço rio-platense, que abrange os territórios do Brasil, Paraguai, Argentina e Uruguai. Cada uma dessas matrizes discursiviza sobre a origem do gaúcho e contribui para construir sua identidade social. Essas questões geográficas e históricas do Rio Grande do Sul nos ajudam a definir um contexto no qual se insere os dois dicionários que analisamos.

O linguajar gaúcho também apresenta características particulares. Existem alguns fatores que contribuem para a linguagem expressiva do povo sul-rio-grandense e que fazem com que essa linguagem seja distinta da linguagem de outras partes do Brasil. Para Callage (1928), são três fatores: o português, o hispano-platino e o aborígene. Segundo o autor, a contribuição aborígene é a menos significativa, pois ela nomeia somente a nomes próprios, de rios e lugares. Pela situação geográfica do estado do Rio Grande do Sul - visto que o Estado faz fronteira com Argentina e Uruguai - Callage justifica que a influência platina é a que mais parece exercer influência na linguagem dos gaúchos.

\section{Análise dos sentidos de china e prenda}

O corpus do nosso trabalho consiste em analisar dois termos típicos do Rio Grande do Sul, china e prenda. Esses dois verbetes são recortados de dois dicionários regionalistas, Vocabulario Gaúcho de Roque Callage e Dicionário de Regionalismos do Rio Grande do Sul, de Zeno Cardoso Nunes e Rui Cardoso Nunes. Trazendo o pressuposto de Petri (2009), de 
Chinas e prendas:

imagens da mulher gaúcha no discurso de dois dicionários regionalistas | 209 que o dicionário mantém e ao mesmo tempo atualiza sentidos, analisamos quais sentidos se mantém e quais se renovam nos termos china e prenda, visto que Vocabulario Gaúcho foi produzido em 1928 e Dicionário de Regionalismos do Rio Grande do Sul em 1984.

\section{CHINA:}

Em Vocabulário Gaúcho, temos a seguinte definição:

subs. mulher de índio; mulher de côr morena carregada, mulher publica.

Em Dicionário de Regionalismos do Rio Grande do Sul, temos:

s. Descendente ou mulher de Índio, ou pessoa do sexo feminino que apresenta algumas das características étnicas das mulheres indígenas/ Cabocla, mulher morena/ Mulher de vida fácil.

Sentidos que se mantém e sentidos que se atualizam: Percebemos que nos dois dicionários, os sentidos se mantém quando remetem a china à etnia indígena, "mulher de índio" e "mulher (de cor) morena". Entendemos que "mulher publica" ou "mulher de vida fácil" dão um sentido pejorativo à palavra china.

\section{PRENDA:}

Em Vocabulário Gaúcho, temos a seguinte definição:

subs: jóia, reliquia, presente de valor.

Em Dicionário de Regionalismos do Rio Grande do Sul, temos:

s. Jóia, relíquia, presente de valor / Em sentido figurado, moça gaúcha.

Sentidos que se mantém e sentidos que se atualizam: Percebemos o sentido de prenda se mantém e ao mesmo tempo se atualiza em Dicionário de Regionalismos do Rio Grande do Sul. Ambos mantém a ideia de "jóia, relíquia, presente de valor", mas o dicionário de Zeno Cardoso Nunes e Rui Cardoso Nunes apresenta um novo sentido: o de "moça gaúcha”. A definição do verbete prenda evidencia efeitos de sentidos de que em um primeiro momento o verbete não designava a mulher gaúcha e sim um objeto antigo, precioso e belo de relativa importância financeira e que é oferecido a outrem. No entanto, em um segundo momento, encontramos que dentro de um contexto particular prenda passa designar a mulher gaúcha. Os efeitos de sentido nesse verbete - sob o nosso olhar são positivos, pois não encontramos termos que possam denegrir a 


\section{0 | Valeria Schwuchow e Felipe Rodrigues Echevarria}

imagem dessa mulher, que é denominada como moça e gaúcha, portanto, temos descrita, de modo bem particular, como é esta prenda, neste caso, uma jovem gaúcha. Destacamos também que a palavra prenda, nos dois dicionários, traz a ideia de "joia", ou seja de de um objeto com valor simbólico, que mais tarde passou também a definir a mulher gaúcha, assim esta carrega uma imagem de algo valoroso.

\section{Conclusões}

Em nossas considerações finais, retomamos a questão da formação social e histórica do Rio Grande do Sul do século XX: um estado que, segundo Eizirik (2002), ao longo dos séculos anteriores, testemunhou várias revoluções e lutas internas e a figura do gaúcho advém desse cenário. A virilidade é uma das principais características do homem gaúcho e como tipo social é "marcado pela bravura que é exigida do homem ao lidar com as forças da natureza e a árdua vida campeira" (OLIVEN, 2006, p. 64). Entendemos que essas são as condições de produção dos dois dicionários que forneceram os dois verbetes que servem de corpus para o presente trabalho. O verbete china, tanto em Vocabulario Gaúcho quanto em Dicionário de Regionalismos do Rio Grande do Sul apresenta sentidos pejorativos, que foram mantidos nos dois instrumentos linguísticos, visto que, na época de produção dos dois dicionários - nesse caso, o século $\mathrm{X}$ - o ambiente era essencialmente dominado por homens no Rio Grande do Sul. Analisando outros verbetes dos dois dicionários, verbetes que ficaram fora da seleção que realizamos para o presente trabalho, percebemos que a maioria está no masculino e isso nos faz entender que tal fato revela as condições sóciohistóricas da época em que os dicionários que serviram objetos de análise de nosso trabalho foram produzidos, ou seja, um Rio Grande do Sul onde a figura feminina tem pouca visibilidade e se dá mais notoriedade à virilidade e bravura do homem gaúcho.

Os sentidos de prenda também são mantidos. A definição de prenda como "Jóia, relíquia, presente de valor" aparece exatamente igual nos dois dicionários. Para Brum (2006), as chinas eram mulheres que seguiam as tropas de soldados gaúchos e estavam sempre à disposição deles. Depois de servi-los, eram abandonadas à própria sorte. Já a prenda, ainda para a mesma autora, é a mulher ou filha do gaúcho, mulheres virtuosas, recatadas e esse recato era exigido também em suas vestimentas, pois o vestido de prenda deve destacar o decoro da mulher gaúcha. Entendemos que prenda tem o sentido de mulher virtuosa, enquanto que china 
Chinas e prendas:

imagens da mulher gaúcha no discurso de dois dicionários regionalistas | 211 representa exatamente o contrário, porém, ainda que os dois verbetes apresentem sentidos distintos, ambos nos permitem perceber a questão da submissão da mulher no Rio Grande do Sul do século XX. Retomando o pressuposto teórico de Petri (2009), de que os dicionários mantêm e ao mesmo tempo atualizam sentidos, percebemos que os sentidos de china e prenda são mais mantidos que atualizados. Em prenda, encontramos nos dois dicionários analisados o sentido mantido de "Jóia, relíquia, presente de valor". Em Dicionários de Regionalismos do Rio Grande do Sul, há uma atualização, pois em Vocabulario Gaúcho a prenda tem somente o sentido de “jóia”, já no dicionário de 1984 aparece o sentido figurado de "moça gaúcha”.

\section{REFERÊNCIAS}

AUROUX, S. A revolução tecnológica da gramatização. 3a ed., Campinas, SP: Editora da Unicamp, 2014.

BRUM, Ceres Karam. "Esta terra tem dono": representações do passado missioneiro no Rio Grande do Sul. Santa Maria/RS: Ed. da UFSM, 2006.

CAllaGE, R. Vocabulario Gaúcho. Porto Alegre: Livraria do Globo, 1928.

EIZIRIK, C.L. Psicanálise e cultura: trajetórias e fronteiras. IN: MARTINS, M. H. (Org.) Fronteiras culturais. São Paulo: Ateliê Cultural. 2002.

FOUCAUlT, M. (1970). A ordem do discurso. 7 ed. Trad. Laura F. de A. Sampaio. São Paulo: Loyola, 2001.

MARIANI, B. Colonização Lingüística: línguas, política e religião no Brasil (séculos XVI a XVIII) e nos Estados Unidos da América (século XVIII). Campinas: Pontes, 2004.

Entre a evidência e o absurdo: sobre o preconceito linguístico.

Dossiê: In: Letras, Santa Maria, v. 18, n. 2, p. 19-34, jul./dez. 2008. 
212 | Valeria Schwuchow e Felipe Rodrigues Echevarria

NEUMANN, E. S. A Fronteira tripartida: a formação do continente do Rio Grande no Século XVIII. In: Capitulos da História do Rio Grande do Sul. Porto Alegre: Ed. UFRGS, 1994. p. 25-46.

NUNES, J. H. Dicionários: história, leitura e produção. In: Revista de Letras (Taguatinga), v. 3, p. 06-21, 2010. Acesso em 11 jun 2016. Disponivel em 〈http://portalrevistas.ucb.br/index.php/RL/article/viewFile/1981/1305 $>$

. O espaço urbano: a "rua" e o sentido público. In: ORLANDI, Eni Pulcinelli (Org.). Cidade Atravessada: os sentidos públicos no espaço urbano. Campinas: Pontes, p.101-109, 2001.

. Sobre a noção de dicionário popular. Estudos Linguísticos (São Paulo), v. XXXV, p. 1028-1032, 2006b. Disponível em: 〈http://www.gel.org.br/estudoslinguisticos/edicoesanteriores/4publicaestudos-2006/sistema06/6.pdf>

. Uma articulação da análise de discurso com a história das ideias liguísticas. In: Letras, Santa Maria, v. 18, n. 2, p. 107-124, jul./dez. 2008.

NUNES, Z.C \& R.C. Dicionário de regionalismos do Rio Grande do Sul. Porto Alegre: Martins livreiro, 1984.

OLIVEN, R. G. A parte e o todo: a diversidade cultural no Brasil-nação. Petrópolis, RG; Vozes, 2006.

ORLANDI, E. P. Análise de discurso: princípios e procedimentos. Campinas, SP: Pontes, 2005.

. História das idéias linguíticas: construção do saber metalingüístico e constituição da língua nacional/ organizadora: Eni Orlandi. Campinas, SP: Pontes; Cáceres, MT: Unemat Editora, 2001.

. Lingua brasileira e outras histórias: discurso sobre a língua e ensino no Brasil. Campinas: RG, 2009.

. Lingua e conhecimento linguistico: para uma história das idéias no Brasil. São Paulo: Cortez, 2002. 
PETRI, V. Reflexões acerca do funcionamento das noções de língua e de sujeito no Dicionário de Regionalismos do Rio Grande do Sul. In: Linguas e instrumentos linguísticos. 23/24 Campinas: Capes-Procad Universidade Estadual de Campinas; 2009 Unicamp, 1997-2009.

. Um outro olhar sobre o dicionário: a produção de sentidos. Santa Maria: UFSM, PPGL Editores, 2010.

SOUSA, R. F. Gramatização, ideologia e as raizes das tecnologias linguísticas. In: Cadernos do IL, Porto Alegre, n. ${ }^{\circ} 44$, p. 149-164, junho de 2012.

STURZA, E. R. Vocabulário sul-rio-grandense: De Instrumento Linguístico à Constituição de um Discurso Fundador. In: Letras e Instrumentos Linguísticos, n. 18, p. 101-121, (jul./dez.2006) Campinas, SP: Universidade Estadual de Campinas: Pontes Editores, 2006.

Recebido em: 16/06/2016

Aceito em: 15/08/2016 
214 | Valeria Schwuchow e Felipe Rodrigues Echevarria 